\title{
Should childhood immunisation be compulsory?
}

\author{
P Bradley Northamptonshire Health Authority, Northamptonshire
}

\begin{abstract}
Immunisation is offered to all age groups in the UK, but is mainly given to infants and school-age children. Such immunisation is not compulsory, in contrast to other countries, such as the United States. Levels of immunisation are generally very high in the $U K,{ }^{1}$ but the rates of immunisation vary with the public perception of the risk of side effects. ${ }^{2}$ This article discusses whether compulsory vaccination is acceptable by considering individual cases where parents have failed to give consent or have explicitly refused consent for their children to be immunised. In particular, the rights of: a parent to rear his/her child according to his/her own standards; the child to receive health care, and the community to be protected from vaccine-preventable infectious disease are considered. The conclusion of the article is that compulsory vaccination cannot, with very few exceptions, be justified in the UK, in view of the high levels of population immunity which currently exist.

(Fournal of Medical Ethics 1999;25:330-334)
\end{abstract}

Keywords: Immunisation; conflict of interest; social responsibility; professional ethics

\section{Introduction}

Infectious disease used to be the major cause of mortality in the UK. Immunisation/vaccination programmes were designed to protect individuals and their communities from infectious diseases. Immunisation programmes have partially lessened the burden of mortality and morbidity of infectious disease, but the decline in disease rates is probably largely attributable to other factors, for example, improved sanitation. There is, however, some evidence of the success of immunisation programmes, where immunisation has eliminated diseases, for example, smallpox. ${ }^{3}$ Also, when immunisation programmes are disrupted, the rates of disease increase, for example diptheria in the USSR. ${ }^{4}$

\section{Individual benefit or benefit for the community?}

Individuals will benefit from immunisation, on average, if the chance of developing morbidity/ mortality from the disease before immunisation, outweighs the chance of developing morbidity $\vec{t}$ mortality after vaccination (including any side effects of the vaccination). It cannot, however, b. guaranteed that a particular individual wiff benefit.

Communities and individuals will benefit from immunisation programmes if immunisation of enough people in a community leads to an overail reduction in the chance of developing a disease That is, because of a decreased chance of contae with the disease. This notion is referred to as here or population immunity. If sufficient people arg immunised the disease may even be eradicatede Levels of immunisation in the UK are currently very high, despite the absence of a compulsoro vaccination policy. ${ }^{1}$ Even so, the rates of immune sation vary in the $\mathrm{UK}$, most commonly ig response to public anxiety about the side effects of vaccination (a very low risk). Epidemiologicat advice suggests that if children were not to be vaç cinated, epidemics could ensue. ${ }^{5}$ However, the conclusion of the article is that compulsory vacc? nation cannot be justified in the UK at present, is view of the high levels of population immunit which currently exist.

What is the procedure by which consent is usuo ally obtained to immunise a child in the UK?

In the UK, immunisation normally takes place in a health care setting during an individual con sultation, when parents or carers accompany the children. Occasionally immunisation takes placke in another setting (for example, a school) and parents entrust their children's safety to professione als. This situation often arises in mass immunisa tion campaigns or when children are in foster care?

In most health districts, there is a policy on ho consent is obtained for immunisation pros grammes. A written invitation is sent to parents for each individual vaccination and consent $\overline{\mathrm{i}}$ obtained from the parent at each clinic visit. I $\overrightarrow{\mathrm{P}_{3}}$ routine circumstances, a child may not be legall $\Phi$ vaccinated until a parent has consented to the procedure. ${ }^{6}$ This legal view considers that the parents' rights to decide on behalf of their childre override health care workers' duties of care. 
In contrast, there are three viewpoints commonly held by health care workers when consent is not obtained from parents to vaccinate their children.

Despite the legal position, health care workers may feel justified in promoting what they see to be the children's interests above their concern to respect parental wishes. However, I will assume that this is an untenable position as most health care workers would not insist on interventions where the benefit to children is small: for example, insisting that seemingly healthy children have routine screening against parental wishes.

Alternatively, in the event of any disagreement, health care workers might feel that respecting parents' choices is the most effective way to promote children's health and that compulsory vaccination would prove counterproductive. A single vaccine is unlikely to offer children reasonable protection against all infectious disease. If parents have not cooperated in the decision, they are less likely to comply with subsequent immunisation or health care interventions.

However, if there is a risk of significant harm to the child, it may be reasonable to override a parental refusal. For example, a child in the early stages of rabies can be, by immunisation, protected from almost certain death. ${ }^{7}$ The health care worker's statutory and moral duty is then to ensure that the child receives the vaccination as the child's life is at stake, no matter what the parental views. ${ }^{8}$ This is also the case if no answer from the parent can be obtained.

In less extreme circumstances, health care workers might instead consider that their professional duty requires them to listen to parents' views when they are available, so that they are fully informed to help each child if the child's health falls below a certain standard, even if this involves acting against parental wishes.

Vaccination against parental wishes may not be justified, if the benefit to the child is insignificant, because of the risk of wronging parents; specifically, the loss of the parents' right to choose health care for their children. Health care workers need to judge whether interventions benefit children sufficiently to justify acting against the parents' wishes.

Can a rights-based approach resolve the dilemma of whether to have compulsory childhood vaccination?

The rights which are relevant to deciding whether vaccination should be compulsory are: children's rights to health care; parents rights to raise their children according to their own standards, and the right of the community to be protected from preventable infectious disease.

\section{How might rights be defined?}

Moral rights are often appealed to as eternal and universal verities although their source is often felt to be obscure. ${ }^{9}$ Rights are sometimes seen to promote selfish action as they are viewed to be the concerns of individuals. However, rights can also protect individuals from being exploited by defining the limits of acceptable behaviour in the community.

The communitarian notion of a right implies that the community has some common moral ground. From this common moral ground, the community can agree that in certain circumstances some actions between agents should be compulsory or outlawed. Hart says: "The concept of a right belongs to that branch of morality which is specifically concerned to determine when one person's freedom may be limited by another's". ${ }^{10}$ Mill points out that rights also have corresponding duties. ${ }^{11}$

The problem with these definitions is that a parent and child could hold conflicting rights. A solution to this problem is the view that rights are not necessarily absolute and that, often, in the case of conflicting rights, one right can be considered overriding. ${ }^{9}$

\section{What are the rights and duties of parents?}

Here it is argued that the parental right to rear is based on a duty of parents to care for their children to an acceptable level. If they fail to care for their children, they relinquish the right to rear. It is felt that a child has a right to be cared for and this includes a right to receive life-saving vaccination when the child already has an easily curable condition, no matter what the views of the child's parent(s).

Several writers state that generally in law the presumption is that parents will make good choices for their children. ${ }^{12-15}$ Others explain that parents have to bear the emotional and financial consequences resulting from health care intervention. However, other writers point out that the children bear the direct consequences of health care, not their parents. ${ }^{12}$ This means parents may not be morally free to make all choices for their children if this acts against the children's interests as perceived by society.

In contrast, some people argue that parents have a right to raise their children according to their own standards without interference. There are several arguments to support this view: I shall consider the most persuasive ones. ${ }^{12}$

First, it is argued that parents are entitled to rear their own children because they are genetically related to them or because the mothers 
declared an interest in the children by bearing them. This may mean that parents are best suited to bond with their children and give them the best care. Unfortunately the bonding process is not inevitable between a parent and a child. Sometimes another carer may form a more suitable relationship with the child. Although genetic relationship is seen as important in our society, it is not automatically enough to entitle a parent to raise his/her child..$^{12}$

Second, families are seen as valuable social institutions, which provide emotional security and foster intimacy and familiarity in children. It is argued that the family needs to be free from interference to fulfil these roles. ${ }^{16}$ This means the family may have a right to privacy.

The right to privacy is derived from the claim that families are intimate entities. ${ }^{13}$ However, Archard suggests that the family relationship is not intimate in the same manner as, for example, a sexual relationship where a third party's interference will prevent the development of the relationship. ${ }^{16}$ If a parent is asked to attend an immunisation for his/her child, so the child's health can be protected, this does not necessarily prove detrimental to the fostering of family relationships.

Archard suggests that the person who has a right to care for the child earns this right by caring for the child. ${ }^{16}$ I make the assumption that most people expect the parent or guardian to provide food, shelter and nurture for the child if $s /$ he is able to do so. Nurture would include parental duties to maintain a child's health to a reasonable level by accessing available health care.

\section{Competing interests}

My own definition of a reasonable standard of health would include major illnesses but would exclude minor problems which, although considered significant by some professionals, would not directly harm the child's health, for example, having crooked teeth. It is difficult to decide into which category a potential immunisation might fit. It seems that such a classification would depend on the balance of benefits and risks to the child. For example, the child in the early stages of rabies should be protected by immunisation no matter what the circumstances. But, a parent who does not want his infant to receive pertussis vaccination is subjecting his child to a smaller health risk. There is also a very slight possibility that the child could be harmed by the vaccination, ie the vaccination might confer long-term brain damage to the child (this is thought unlikely). ${ }^{17}$

This does not mean parents are obliged to optimise a child's interests, ${ }^{12}$ because of the competing interests of other children and the interests of the parents themselves. ${ }^{12}$

In other words, if parents fail to maintain minimal level of care, they relinquish their right rear. ${ }^{18} 19$ Health care workers should at leas consider whether children's rights to basic car override parents' right to choose. We shall returf to this point later. ${ }^{12} 20$

What rights does the community have? $\vec{\circ}$ Another potential "right" needs to be considered before it can be decided whether compulsory vae cination is an acceptable policy in the U/F namely, the right of every individual in the community to be protected from infectious disease, by insisting on high levels of childhoof vaccination. The grounds for such a right woule be that non-immunised children pose a greater risk of infection to the community than immus nised children.

It is difficult to argue that the community general has a right to demand compulsory immis nisation from all members in the communit Individual immunisation offers a high level $\$$ protection from communicable disease and is readily available to the whole population. The ris of infection from an unimmunised child to a immunised individual will usually be very small. seems therefore, the best option for persons wo ried by the threat of infectious disease would be to ensure that they themselves are immunised, rathe than insisting on compulsory vaccination for all.?

Despite this, there will be some groups who cannot be immunised, for example, they may be too young to receive immunisation or they ma have another medical condition which preveng them from being immunised, for example leukae mia. These people are more at risk from non-immunised individuals.

However, levels of population immunity or vac cine uptake are generally high in the UK for con ditions where vaccination is available. For oth diseases, poor access or non-availability of vacc太 nation explain low levels of population immunitio rather than low levels of uptake. ${ }^{1}$ If a small minok ity of parents decide not to have their childreg vaccinated, it is unlikely to alter significantly the level of population immunity and the chance of susceptible individuals contracting infectious dis ease. Because of this the community does not have a right to insist that all children are immunise $\Phi$ even to protect vulnerable persons.

However, the right of the community to be prof tected from infectious disease does seem to have some validity. The right seems to imply a duty on behalf of the health care system to offer immung sation to all those at risk of contracting commun 
cable disease where a suitable, effective vaccine is available and the costs are not prohibitive.

\section{What rights do children have?}

Children do not necessarily have claim rights to health care in all circumstances, if treatments are of dubious effectiveness or are very expensive. However, it seems reasonable that they have a right to vaccination, if the danger of a severe infection is great and a safe vaccine is available, ie the chances of benefit to children greatly outweigh the chances of harm. It seems that this right outweighs any rights parents have to choose. Social services have statutory legal powers to organise such vaccinations through the courts.

However, most immunisations given to children in the UK do not show benefits of such magnitude. This is because, in the UK, most vaccine-preventable infectious diseases have become rarer and show a significant degree of population immunity, lessening the chances of children contracting them. In these cases, it becomes much more difficult to decide whose rights are overriding, parents' or children's.

If a child is due to receive an immunisation where the benefits to the child could be significant but not immediately life-saving and the parent has repeatedly not replied to the request for consent and is not present, the immunisation cannot go ahead because of the current legal position. An example of this would be a child in foster care.

Non-vaccination will increase the risk of serious infectious disease, but the increase is difficult to quantify. In contrast, most immunisations are procedures of very low risk. Generally, parents attach great importance to being involved in the decision making process for immunisation of their child $^{6}$ but may accept the results of immunisation even if they were not present and had not given consent, for example, parents of children who are inadvertently immunised in mass campaigns. In view of these considerations, immunisation might sometimes be justified if the likely benefits far outweigh the likely harm. More research is needed into the opinions of parents who repeatedly fail to give consent for the vaccination of their child and the quantification of risks and benefits for the child. If a majority of such parents were to object strongly and/or the level of benefit to an individual child was small, the decision might need to be reversed.

\section{Conclusion}

In this article, the issue of whether there should be a compulsory vaccination programme has been discussed. In particular, it has concentrated on the dilemmas health care workers face when they try decide whether it is morally justifiable to vaccinate a child where parental permission is refused or problematic.

Health care workers cannot justify compulsory immunisation for children against parents' wishes, purely in terms of the consequences that their actions yield. Parents can be wronged if their wishes are ignored and usually their wishes should be considered overriding. However, if children are considered to be in danger of being harmed significantly, their wellbeing is the primary concern.

Health care workers' decisions whether or not to consider parents' views as overriding, should be based on consideration of the respective rights of parents and children, namely parents' rights to rear their child according to their own standards and the children's rights to health care. Children's rights to health care at least include the right of access for vaccinations which prevent otherwise inevitably fatal diseases. Parents must maintain a minimal level of care for their children to earn their rights to rear according to their own standards.

If children are suspected of having a potentially fatal condition preventable by vaccination, such as rabies, and consent has been requested without reply, the immunisations should go ahead even if legal action might be needed to do this.

However, it is not easy to argue that a child has a right to a vaccination when the balance of harms and risks is less obvious. Generally a child who is assumed to be well should not be immunised if the parent has refused, as the parent could be wronged. This is the case for most vaccinations in the UK, where protection is given for diseases which are not very prevalent or where there is already a high degree of population immunity.

In conclusion, it seems that a policy of compulsory vaccination cannot be justified, as the present system of non-compulsory vaccination promotes high levels of population immunity. However, if the level of population immunity were to fall for a particular vaccine-preventable infectious disease, compulsory vaccination might become a morally justifiable option.

\section{Acknowledgements}

I would like to thank Jennifer Jackson, Director of the Centre for Professional Ethics at Leeds University, who helped me prepare arguments used in this article.

P Bradley, MBBS, MRCGP, $M A$ (Health Care Ethics), MPH, DCCH, is Specialist Registrar in Public Health Medicine, Northamptonshire Health Authority, Northampton. 


\section{References}

1 Salisbury DM, Begg NT, eds. 1996 Immunisation against infectious disease. London: HMSO, 1996: inside cover.

2 Calman K. From the Chief Medical Officer: measles, mumps, rubella (MMR) vaccine, Chron's disease and autism. London: Department of Health, 1998:1-4

3 Donaldson RJ, Donaldson LJ. Essential public health medicine. London: Kluwer Academic Publishers, 1993: 454.

4 See reference 1: 69.

5 Calman K. From the Chief Medical Officer: national measles and rubella immunisation campaign. London: Department of Health, 1994: $1-5$

6 See reference 1: 7 .

7 See reference 1: 186

8 Department of Health. Children Act. London: HMSO, 1989: part V, ch 41 .

9 Beauchamp TL, Childress JF. Principles of biomedical ethics. Oxford: Oxford University Press, 1994: 69-85

10 Hart HLA. Are there any natural rights? In: Waldon J, ed. Theories of rights. Oxford: Oxford University Press, 1984: 79

11 Mill JS. On moral obligation and justice. In: Acton HB, e Utilitarianism. London: JM Dent and Sons, 1972: 40-2.

12 Buchanan AE, Brock DW. Deciding for others: the ethics of surre? gate decision making. Cambridge: Cambridge University Pre 1989: 230-6.

13 Dworkin G. The theory and practice of autonomy. Cambridge Cambridge University Press, 1988: 89-103.

14 Koocher GP, Speigel PC. Children, ethics and the law. Univers of Nebraska Press, 1990: 13.

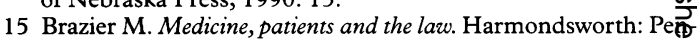
guin, 1992: 95.

16 Archard D. Children, rights and childhood. Routledge, 1999: 104-30.

17 See reference 1: 159-60.

18 Holder A Legal issues in paediatric and adolescent medicine. Y. University Press, 1985: 102-9.

19 Bainham A, Creaney S. Children: the modern law. Jordan, 1990 93.

20 See reference 16: 10

\section{News and notes}

\section{Not My Child ... an Information Sheet for Potential Gamete Donors}

The Donor Conception Support Group of Australia Inc has produced a leaflet for people considering donating sperm, ova or embryos to help those with infertility problems who wish to conceive a child.
To obtain a copy of the leaflet contact: The Donor Conception Support Group of Australia Inc, PO Box 53, Georges Hall, NSW 2198, Australia. Telephone: (02) 97241366.

\section{News and notes}

\section{Third Annual European Biotechnology Business Congress}

EuropaBio '99, the third annual business congress on biotechnology, will take place in Munich between November 16 and 19, 1999. The conference will focus on biotechnology for economic growth and improved quality of life.
For further information please contact: Congress Secretariat, EuropaBio '99, Avenue de l'Armee 6, B-1040 Brussels, Belgium.Tel: +32 2735 0313; fax: +32 2735 4960; e-mail: mail@europa-bio.be; website: http://www.europa-bio.be 